\title{
Acylated Ghrelin increases in young adults with obesity due to lack of sleep
}

Reyna-Echeveste EI ${ }^{1}$, Beltrán-Campos V²*, Tolentino Ferrel MR ${ }^{3}$, García Campos ML ${ }^{1}$, Jiménez-García SN³ ${ }^{3}$ Ramírez-Gómez XS ${ }^{1}$, Blancarte Fuentes $\mathbf{E}^{\mathbf{1}}$

${ }^{1}$ Division of Health Sciences and Engineering, Department of Clinical Nursing, Campus Celaya-Salvatierra, University of Guanajuato; Celaya, Guanajuato, Mexico.

${ }^{2}$ Division of Health Sciences and Engineering, Campus Celaya-Salvatierra, University of Guanajuato; Celaya, Guanajuato, Mexico.

${ }^{3}$ Division of Health Sciences and Engineering, Department of Nursing and Obstetrics, Campus Celaya-Salvatierra, University of Guanajuato; Celaya, Guanajuato, Mexico.

*Corresponding Author: Vicente Beltrán Campos, Division of Health Sciences and Engineering, Campus Celaya-Salvatierra, University of Guanajuato; Celaya, Guanajuato, Mexico.

\section{Received Date: July 072021 | Accepted Date: August 132021 | Published Date: August 182021}

Citation: Reyna-Echeveste EI, Beltrán-Campos V, Tolentino Ferrel MR, García Campos ML, Jiménez-García SN, et al. (2021) Acylated Ghrelin increases in young adult with obesity due to lack of sleep. J. Endocrinology and Disorders. 5(4): DOI: 10.31579/ 26401045/079

Copyright: () 2021 Vicente Beltrán Campos, This is an open-access article distributed under the terms of the Creative Commons Attribution License, which permits unrestricted use, distribution, and reproduction in any medium, provided the original author and source are credited.

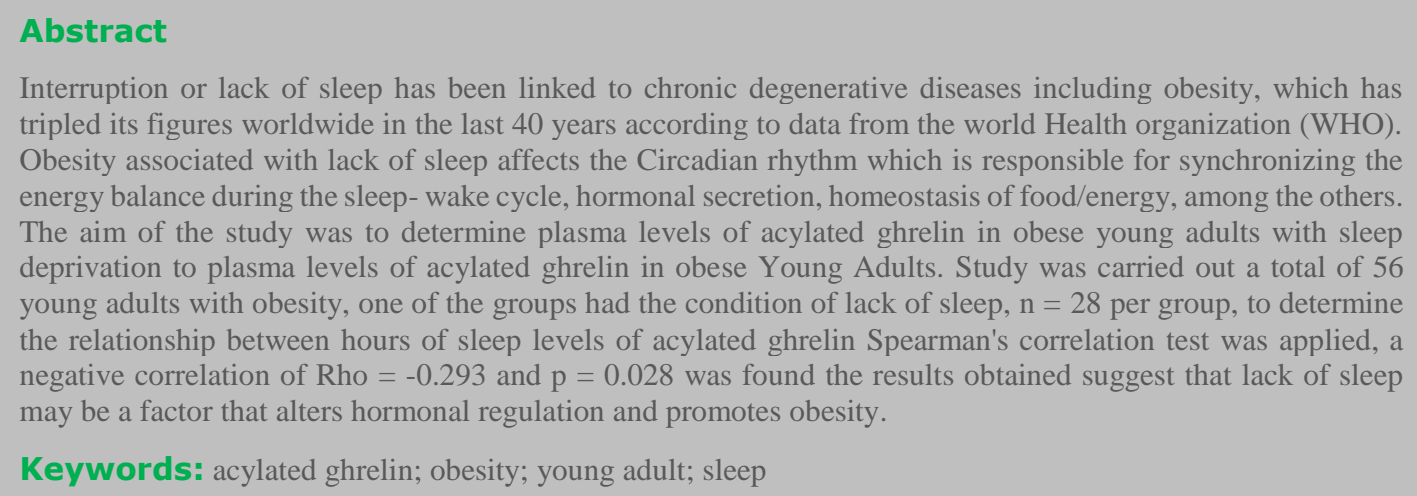

\section{Introduction}

The interruption or lack of sleep (LS) is associated with the increased neuroendocrine activity of the hypothalamus-pituitary-adrenal axis and the sympathetic system [1]. It affects immunological, metabolic responses, synchronicity of the circadian rhythm and neuroendocrine rhythm, promotes factors that trigger cardiovascular diseases, diabetes, hypertension, dyslipidemias, metabolic syndrome, and obesity [2-4].

Obesity has tripled its figures worldwide in the last 40 years according to data from the World Health Organization (WHO) [5], starting at increasingly early ages and is considered the leading cause of death, due to its comorbidities and complications, which are the first cause of consultation at all levels of care and generate high costs in health services [6].

Obesity associated with lack of sleep affects the Circadian rhythm; which is responsible for synchronizing the energy balance during the sleep-wake cycle, hormonal secretion, body temperature regulation, food/ energy homeostasis [7], cell cycle regulation [8], tissue and organic [9], as well how to ensure maximum activity time both individual, behavioral and physiological cells occur at the right time of day, in addition to governing the time and duration of sleep [10].

During phases I and IV of sleep (non-REM, NREM), endocrine activation [11] is generated, determined by the secretion of growth hormone $(\mathrm{GH})$ $[12,13]$ and secondarily the secretion of ghrelin which it allows to make a positive feedback allowing to raise the GH levels [14], and the energy expenditure; this promotes the release of hormones that regulate food intake and satiety [15]. However, some studies have shown that LS itself allows the elevation of ghrelin levels (Ghr), which increases food consumption and secondarily to the generation of obesity [16]. Ghr is secreted mainly by endocrine cells of the enteric system type X/A [17, 18], is found in the bloodstream in higher concentrations as desoctanoyl or desacyl-ghrelin or deacylated Gh [19-21], and as Ghr acylated or acyl 
ghrelin, the latter responsible for the biological effects [22, 23]. Ghr levels promotes activation of the orexigenic hypothalamic axis [24], where rAgouti protein (AgRP) and neuropeptide Y (NPY)[25] are secreted, both related to higher food consumption [23]. In addition, effects on the Central Nervous System (CNS) [26], on the regulation of adipokines and on immune functions $[18,27]$ are attributed. At the CNS level, a direct action on hypothalamic neurons activating protein kinase (AMPK) $[28,29]$ has been reported, which establishes and inhibition of acetyl-CoA carboxylase [28], increases mitochondrial metabolism and generation of reactive oxygen species; these events induce the expression of orexigenic neuropeptides [30,31] and intervene in the activation of the mTor cytoplasmic nutrient sensor at the hypothalamic level [32], which maintains orexigenic function, which implies a dependence of the detection of nutrient in the pathway signaling of acyl ghrelin[33].

In studies conducted in animal models, the presence of Ghr immunoreactive cells has been demonstrated through immunohistochemical techniques, distributed in different areas of the hypothalamus such as the paraventricular, ventromedial, arcuate, dorsomedial, and lateral hypothalamus nuclei, proposing their participation in the regulation homeostatic, endocrine and autonomic $[34,35]$. Other studies in laboratory animals, which were administered $\mathrm{Ghr}$ in the paraventricular and lateral hypothalamic nuclei, showed that its administration allows these animals to stay awake., reducing the sleep of slow wave so non- REM (NREM) fast wave sleep or REM sleep, accompanied by increased need for food consumption [36,37]. In addition, when subjecting laboratory mice to a lack of sleep of 5 hours, an increase in the content of the hypothalamic Ghr was observed during the first hour of the lack of sleep, as well as; an increase in corticosterone (CORT) [38], and an increased in food consumption that is related to the increase in Ghr [15]. In addition, it has been shown that the secretion of this hormone occurs after the secretion of growth hormone during the NREM phase and before starting the REM phase of physiological sleep [14]. So, blood levels of this hormone exhibit a circadian fluctuation that aligns with meals, with preprandial elevation followed by rapid postprandial reductions [39]. Ghr contributes to the regulation of body weight that could be involved in the modification of somatometric parameters such as body mass index (BMI). On the other hand, in a study conducted by Broussard et.al., where plasma levels of total ghrelin were measured in 19 men with normal BMI, to see their eating behavior, it was shown that lack of sleep raises ghrelin levels compared to men with sleep restriction; finding a correlation of lack of sleep with higher calorie intake [40]. These authors recommend studies that assess the hormonal homeostatic factor.

Chapman et. al., in another study whose objective was demonstrate whether acute sleep deprivation affects food purchase options in a simulated supermarket, where 14 men with normal BMI were subjected to lack of total sleep. They find that there is a positive relationship between lack of sleep and the purchase of a greater number of highcalorie foods compared to purchases made after a normal 8 hour sleep night. In addition, no relationship was found with total Ghr levels [41]. Andarini et. al., in an experimental study, whose objective was to compare acylated ghrelin levels and appetite ranges at different times, in two groups of 16 subjects, one with obesity and normal BMI, it was shown that the levels of acylated ghrelin were higher in participants with normal BMI compared to the obesity group. There are no differences in appetite ranges between groups at different measurement times, nor was a correlation found between acylated Ghr levels and appetite ranges [42]. There are still controversies between the different studies on the relationship between lack of sleep, obesity and acylated ghrelin levels, which allows us to determine if the variations of this hormone have a direct influence on food consumption. This article aims to identify the relationship between lack of sleep and acylated ghrelin levels in young Adults with obesity.

\section{Materials and method}

Study was conducted with 56 young adults with obesity from the city of Celaya, Guanajuato, Mexico; divided into 2 groups. Control group with 28 young people with obesity without lack of sleep; group cases with 28 young people with obesity and lack of sleep. For the exclusion criteria, the diagnosis of chronic degenerative diseases such as hypertension, diabetes, sleep disorders, Prader Willis syndrome, who were under medical treatment to fall asleep, as well as the use of psychoactive substances.

The information of sociodemographic data was obtained through the selfapplication of data card; prior authorization and signed informed consent.

The weight and height measurement were performed for the calculation of the body mass index, subsequently the blood was collected in a tube with EDTA and Pierce 88265 protease inhibitor by venous puncture. The blood was centrifuged at $3500 \mathrm{rpm}$ at $4^{\circ} \mathrm{C}$, the plasma was separated for storage at $-20^{\circ} \mathrm{C}$ until the level of acylated ghrelin levels was determined, using the ELISA technique.

\section{Determination of Acylated Ghrelin Levels}

For the determination of plasma acylated ghrelin hormone levels, using the ELISA technique, the Acylated ghrelin (human) express enzyme immunoassay kit\# A05106.96 wells kit, Bertin pharma Brand, was used according to the manufacturer's specifications.

\section{Data analysis}

The analysis of the results was carried out through the statistical package SPSS 24.

Descriptive statistics were applied for sociodemographic variables; for the numerical ones, central tendency measures were applied and for the categorical ones, frequencies (f) and percentages (\%) were determined. For the analysis of the differences of means between the groups in the values of weight, height and BMI, the Student t test was applied for independent samples. After the analysis with the Levene test, the Mann Whitney U test was applied to obtain the mean difference; as well as Spearman's correlation coefficient to determine the relationship between lack of sleep and elevated ghrelin levels, with an error value of 0.05 .

\section{Ethical and legal considerations}

All subjects gave their informed consent for inclusion before they participated in the study. The study was conducted in accordance with the Declaration of Helsinki.

The research project was approved by the Research Committee and the Bioethics Committee of the Celaya-Salvatierra Campus of the University of Guanajuato, with registration numbers CIDSC-3532910 and CBCCS01626112018 respectively.

\section{Results}

\section{Sociodemographic data}

The sociodemographic data collected through a questionnaire, applied to a total of 56 participants $(n=56)$, distributed in 2 groups, control group (CG) and case group $(\mathrm{CaG})$ with a total of 28 participants each, showed that the average age of the participants in the GC is $22.11 \pm 1.72$ years and for the $\mathrm{CaG} 21.36 \pm 2.34$, a predominant degree level of studies was found with $3.6 \%$ of the GC and $14.3 \%$ of the CAG study and work, the most common religion was the catholic with $89.3 \%$ in the GC and 71.4 in the $\mathrm{CaG}$ (Table 1) 


\begin{tabular}{|c|c|c|c|c|c|}
\hline & \multicolumn{2}{|l|}{ CG } & \multicolumn{3}{|l|}{$\mathrm{CaG}$} \\
\hline & \multicolumn{2}{|l|}{$\mathrm{M} \pm \mathrm{SD}$} & \multicolumn{3}{|c|}{$\mathrm{M} \pm \mathrm{SD}$} \\
\hline \multirow[t]{3}{*}{ Age } & \multicolumn{2}{|l|}{$22.11 \pm 1.72$} & \multicolumn{3}{|c|}{$21.36 \pm 2.34$} \\
\hline & & \multicolumn{2}{|c|}{ CG } & \multicolumn{2}{|c|}{$\mathrm{CA}$} \\
\hline & & fr & $\%$ & fr & $\%$ \\
\hline \multirow{4}{*}{ Education level } & Postgraduate & 0 & 0 & 2 & 7.1 \\
\hline & Bachelor's degree & 20 & 71.4 & 21 & 75 \\
\hline & technique & 0 & 0 & 1 & 3.6 \\
\hline & High school & 8 & 28.6 & 4 & 14.3 \\
\hline \multirow{4}{*}{ Occupation } & Student & 19 & 67.9 & 22 & 78.6 \\
\hline & Student- employee & 1 & 3.6 & 4 & 14.3 \\
\hline & Employee & 7 & 25 & 2 & 7.1 \\
\hline & Unemployed & 1 & 3.6 & 0 & 0 \\
\hline \multirow{4}{*}{ Religion } & Catholic & 25 & 89.3 & 20 & 71.4 \\
\hline & Agnostic & 0 & 0 & 2 & 7.1 \\
\hline & Christian religion & 2 & 7.1 & 0 & 0 \\
\hline & Does not mention & 1 & 3.6 & 6 & 21.4 \\
\hline
\end{tabular}

fr: frequency, M: Mean, SD: standard deviation, \%: percentage.

Table 1: The Sociodemographic Data

\section{Anthropometric data}

The analysis of the results obtained by Student's $t$ test for weight measurements, showed that there is no statically significant difference with a $t_{(1,54)}=$ -0.783 ; for measurement of body height $\mathrm{t}_{(1,54)}=0.192$, and for BMI $\mathrm{t}_{(1.54)}=-0.695$ when comparing the CG against the CaG (Table 2).

\begin{tabular}{|l|c|c|c|}
\cline { 2 - 4 } \multicolumn{1}{c|}{} & CG & CaG & P Value \\
\cline { 2 - 4 } \multicolumn{1}{c|}{} & $\mathrm{M} \pm \mathrm{SD}$ & $\mathrm{M} \pm \mathrm{SD}$ & 0.437 \\
\hline Weight & $101.18 \pm 16.12$ & $105.21 \pm 22.01$ & 0.849 \\
\hline Height & $1.73 \pm 0.72$ & $1.73 \pm 0.80$ & 0.522 \\
\hline
\end{tabular}

M: Mean, SD: standard deviation

Table 2: Anthropometric data

\section{Hours of sleep and levels of acylated ghrelin}

For the analysis of the values obtained from the total hours of sleep and levels of acylated ghrelin, the Mann Whitney U test was applied, where it was shown that there are statistically significant differences with respect to the total hours of sleep when comparing both groups with a $\mathrm{U}=0.0001$, mid-range for the $\mathrm{CG}=42,500$ and for the $\mathrm{CaG}=14,500$.
With respect to the results obtained from ghrelin levels, it showed that there are statistically significant differences when comparing both groups with a $\mathrm{U}=234, \mathrm{p}=0.0096$, and mid-range for the $\mathrm{CG}=22.857$ and for the $\mathrm{CaG}=34.143$ (Table 3).

\begin{tabular}{|l|c|c|c|c|c|}
\cline { 2 - 6 } \multicolumn{1}{c|}{} & \multicolumn{2}{c|}{ CG } & \multicolumn{2}{c|}{ CaG } & Pum of \\
\cline { 2 - 6 } \multicolumn{1}{c|}{} & \begin{tabular}{c} 
Sunges \\
\multicolumn{1}{c|}{}
\end{tabular} & Middle range & Sum of ranges & Middle range & P value \\
\hline $\begin{array}{l}\text { Total hours of } \\
\text { sleep }\end{array}$ & 1190.000 & 42.500 & 406.000 & 14.500 & $<0.0001$ \\
\hline $\begin{array}{l}\text { Acylated } \\
\text { ghrelin levels }\end{array}$ & 640.000 & 22.857 & 956.000 & 34.143 & 0.0096 \\
\hline
\end{tabular}

M: Mean, SD: standard deviation

Table 3: Hours of sleep and levels of acylated ghrelin

\section{Association between sleep hours and Acylated ghrelin plasma levels}

To determine the relationship between sleep hours and acylated ghrelin levels, the Spearman correlation test was applied, showing a negative correlation $\mathrm{Rho}=-0.293$ and $\mathrm{p}=0.028$, indicating a moderate correlation, implying that at a lower correlation hour of sleep there are higher levels of acylated ghrelin.

\section{Discussion}

The results obtained in this research we can propose the existence of an inverse relationship between lack of sleep and plasma levels of acylated ghrelin in young people with obesity, which implies that shorth-term sleep or lack of sleep may be a factor that alters hormonal regulation and is associated with a greater probability of promoting obesity and increased adiposity $[43,44]$.

This lack of sleep permeates a dysregulation of the neuroendocrine system, allows the elevation of orexigenic hormones such as ghrelin; that, together with ghrelin, leptin and dopamine; they are involved in the 
increase in the need for energy consumption and the maintenance of food reward systems, so they are perceived as appetite regulators [42, 45, 46]. As ghrelin is one of the main hormones related to preference of high palatability and high calorie food regardless of metabolic requirements [47, 48]; high concentrations of this could be a cause in the increase and /or difficulty for weight loss [49]. Therefore, its regulation should be proposed in the diagnosis and comprehensive treatment plans of the patient with obesity.

Important coincidence of the results of this study with those obtained by DelParigi et al., where it reports an increase in ghrelin hormone in patients with Prader Willi syndrome, points to ghrelin as the main factor of hyperphagia [50]. In addition, Kweh et al., propose that the increase in ghrelin during childhood is a predictor of obesity [51].

Another study conducted through functional magnetic resonance imaging in obese and non- obese subjects, showed that the activation of various brain areas such as the ventral striatum, the ventromedial prefrontal cortex, and the extra striated visual cortex, related to reward phenomenon. On the other hand, greater activations related to reward in the dorsolateral prefrontal cortex and posterior precuneus cluster of obese subjects were observed; compared to non-obese [52]. Consistent with this, obese subjects exhibited longer election times after repeated rewards and circulating ghrelin levels lower than lean controls. Reduced ghrelin levels significantly predicted slower post- rewards and circulating ghrelin levels lower than lean controls. Reduced ghrelin levels significantly predicted slower post- reward choices and reward- related hyperactivity in the dorsolateral prefrontal cortices in obese subjects [52].

Perhaps ghrelin signaling on the posterior hippocampus- hypothalamusbrain pathway is affects, by counteracting satiety signals at the intestinal level, allowing the increase in the amount of food ingested. Ghrelin and orexin interact to increase the need for energy consumption through a downward signaling pathway from the hippocampus to the hindbrain [53]. On the other hand, Andarini et, al., relate the subtype of acylated ghrelin with the qualification of self- reported appetite in obese subjects with normal body index, when determining acylated ghrelin before food consumption and 30, 60 and 120 minutes after food consumption showed that acylated ghrelin levels remained increased in obese subjects compared to the control group [42]. Thus, ours results of the correlation between obesity and plasma ghrelin levels support the results of this study.

Contrary to the data shown by Quian et. al., point out that circadian misalignment increases appetite for calorie- rich foods, in addition to raising postprandial levels of acylated ghrelin [54]. Likewise, Aly et. al., reported that ghrelin levels are lower in children with obesity [55]. Another study in laboratory animals showed that increase in ghrelin does not favor the reward system and orexigenic effects, proposed a mechanism that favors resistance to ghrelin, whose function is to prevent starvation and not promote obesity [56]. So, so far, the data referring to this relationship remain controversial.

\section{Conclusions}

The present study yielded results that allow us to support the obesity approach from the neuroendocrine point of view and the factors involved in it through new mechanisms. Because lack of sleep is a new health problem that leads to appearance of chronic diseases, it is a suggested to intervene early in the diagnosis and treatment of sleep disorders and obesity.

It is recommended to carry out new studies that support this relationship, which will determine a causal relationship (Randomized Controlled Studies, RTC) and double blind, to achieve control of the intervening variables; it is also suggested to contrast the studies found with subjects of normal weight, to enrich the results found in this research.

\section{Author contributions}

The authors REEI and BCV, worked equally in the experimental development and in the writing of the article, these authors have contributed equally to this work and share first authorship. The author TFMR participated in the data collection, CGML and JGSN participated in the review of the article and the experimental design, RGXS and BFE in the search for references, all authors reviewed the final version of the article.

\section{Funding}

The University of Guanajuato supports the financing of laboratory reagents and the publication of this article.

\section{Acknowledgments}

The authors thanks Francisco Corona Palmerin and Miriam Cervantes Tolentino, students of the Degree in Nutrition, María Guadalupe Botello Jacuinde student of the Master's degree in Nursing Sciences of the University of Guanajuato Campus Celaya- Salvatierra.

\section{Conflicts of interest}

The authors declare that the research was conducted in the absence of any commercial or financial relationships that could be construed as a potential conflict of interest.

\section{References}

1. Medic G, Wille M, Hemels ME. (2017). Short- and long-term health consequences of sleep disruption. Nat Sci Sleep. 19(9):151-161.

2. Lundsford- Avery J, Engelhard M, Navar A, et al. (2018). Validation of the sleep regularity index in older adults and associations with cardiometabolic risk. Scientific reports. 14158:1-11.

3. Broussard J, Van Cauter E. (2017). Disturbances of sleep and circadian rhythms: Novel risk factors for obesity.Curr Opin Endocrinol Diabetes Obes. 23(5): 353-359.

4. Noh J. (2018). The effect of circadian and sleep disruptions on obesity risk.J Obes Metab Syndr. 27(2):78-83.

5. Organización Mundial de la Salud. (2018). Obesidad y Sobrepeso. Organización Mundial de la Salud.

6. Ju Y, McLeand J, Toedebusch C, et al. (2013). Sleep quality and preclinical Alzheimer Disease. JAMA Neurol. 70(5):587593.

7. Takahashi J. (2017). Transcriptional architecture of the mammalian circadian clock. Nat Rev genet. 18(3):164-179.

8. Onaolapo A Y, Onaolapo O J. (2018). Circadian dysrhythmialinked diabetes mellitus: Examining melatonin's roles in prophylaxis and management. World Journal of Diabetes 9(7):99-114

9. Bonny O, Vinciguerra M, Gumz M, et al. (2013). Molecular bases of Circadian rhythmicity in renal physiology and pathology. Nephrol Dial Transplant. 28(10):2421-2431.

10. Yan L., Silver R. (2015). Neuroendocrine underpinnings of sex differences in Circadian timing systems. HHS Author Manuscript. 118-126.

11. Silva-Costa A, Harter Griep R, Rotenberg L. (2017). Nigth work and BMI: is it related to on-shift napping?. Revista de Saude Publica.

12. Velayos J L, Moleres F J, Irujo A M, et al. (2007). Paternain B. Bases anatómicas del sueño. Anales Sis San Navarra. 30(Suppl 1):7-17.

13. Reddy S., Sharma S., Physiology, Circadian rhythm, StatPearls (internet) (2018). Treasure Island. 
14. Kim TW, Jeong J, Hong S. (2015). The Impact of Sleep and Circadian Disturbance on Hormones and Metabolism. International Journal of Endocrinology. Article ID 591729, 9.

15. García-García F, Juárez- Aguilar E, Santiago- García J, et al. (2014). Ghrelin and its interactions with growth hormone, leptin and orexins: implications for the sleep- wake cycle and metabolism. Sleep Medicine Reviews. 18: 89-97.

16. Westerterp-Plantenga MS. (2016). Sleep, circadian rhythm and body weight: parallel developments. Proceedings of the nutrition society. 75(4): 431-439.

17. Barreiro M, Gaytan F, Caminos J, et al. (2002). Cellular location and hormonal regulation of ghrelin expression in rat testis. Biol Reprod. 67(6): 1768-1776.

18. Stengel A, Taché Y. (2012). Ghrelin - a pleiotropic hormone secreted from endocrine x/a-like cells of the stomach. Front Neurosci. 6(24).

19. Andrews Z. (2011). Central mechanisms involved in the orexigenic actions of ghrelin. 32(11), 2248-2255.

20. Korbonits M, Goldstone A P, Gueorguiev M, et al. (2004). Ghrelin--a hormone with multiple functions. Front Neuroendocrinol. 25(1), 27-68.

21. Mirzaie B, Mohaddes G, Ebrahimi H, et al. (2014). Ghrelin increases lymphocytes in chronic normobaric hypoxia. Adv Pharm Bul. 4(4):339- 343.

22. Castañeda T, Tong J, Datta R, et al. (2010). Ghrelin in the regulation of body weight and metabolism. 31(1): 44-60.

23. Sato T, Nakamura Y, Shiimura Y, et al. (2012). Structure, regulation and function of ghrelin. J Biochem. 151 (2): 119128.

24. Kojima M. (2008). The discovery of ghrelin--a personal memory. Regulatory Peptides. 145(1-3): 2-6.

25. Kojima M, Kangawa K. (2005). Ghrelin: structure and Function. Physiol rev. 85(2): 495-522.

26. Masuda M, Tanaka T, Inomata N, et al. (2000). Ghrelin stimulates gastric and motility in rats. Biochemical and Biophysical research communications. 276(3): 905-908.

27. Siegl D, Midura E, Annecke T, et al. The effect of ghrelin upon the early inmune response in lean and obese mice during sepsis. Plos one. 10(4): 0122211.

28. Ulrika A, Filipsson K, Abbott C, et al. AMP- activated protein Kinase plays a role in the control of food intake. The Journal Biological of Chemistry. 279:12005-12008.

29. Kola B, Farkas I, Christ-Crain M, et al. The orexigenic effect of Ghrelin is mediated throught central activation of endogenous cannabinoid system. Plos one. 3(3), 1797.

30. Andrews ZB, Liu ZW, Wallingford N, et al. (2008). UCP2 mediates ghrelin's action on NPY/AgRP neurons by lowering free radicals. Nature. 454(7206): 846-851.

31. Stevanovic D, Trajkovic V, Müller-lühlhoff, et al. (2013). Ghrelin-induced food intake and adiposity depend on central Mtorc1/S6K1 signaling. Mol Cell Endocrinol. 381(1-2): 280290.

32. Lim CT, Kola B, Korbonits M. (2010). AMPK as a mediator of hormonal signalling. J Mol Endocrinol. 44(2): 87-97.

33. Da Silva J, Da Silva F, Mendes P. (2017). The impact of ghrelin in metabolic Diseases: an inmune perspective. J Diabetes Res. 4527980.

34. Horvath T, Abizaid A, Dietrich M, et al. (2012). Ghrelinimmunopositive hypothalamic neurons tie the Circadian clock and visual system to the lateral hypothalamic aurosal center. Mol Metab. 1(1-2): 79-85.

35. Challet E. (2015). Keeping Circadian time with hormones. Diabetes, Obesity and Metabolism. 17(suppl. 1):76-83.
36. Szentirmai E, Kapas L, Krueger JM. (2007). Ghrelin microinjection into forebrain sites induces wakefulness and feeding in rats. American Journal of Physiology-Regulatory integrative and comparative physiology. 292: R575-R585.

37. Szentirmain E. (2012). Central but not systemic administration of ghrelin induces wakefulness in mice. Plos one.

38. Bodosi B, Gardi J, Hajdu I, et al. (2004). Appetite, Obesity, Digestion, and metabolism. 287(5): R1071-R1079.

39. Howick K, Griffin B, Cryan J, et al. (2017). From Belly to brain: Targeting the ghrelin receptor in appetite and food intake regulation. Int J Mol Sci. 18 (2): 273.

40. Broussard J, Kilkus J, Delebecque F, et al. (2016). Elevated ghrelin predicts food intake during experimental sleep restriction. Obesity (Silver Spring). 24 (11).

41. Chapman C, Nilsson E, Nilsson V, et. al. (2013). Acute sleep deprivation increases food purchasing in men. Obesity. 21 (12): 555-560.

42. Andarini S, Kangsaputra FB, Handayani D. (2017). Pre- and postprandial acylated ghrelin in obese and normal weight men. Asia PacnJ Clin Nutr. 26(Suppl 1): 85-91.

43. Ogilvie R, Patel S. (2017). The epidemiology of sleep and Obesity. Sleep health.3 (5): 383-388.

44. Nedeltcheva A, Kilkus J, Imperial J, et al. (2009). Sleep curailment is accompanied by increased intake of calories from snacks. Am J Clin Nutr. 89(1):126-133.

45. Dickson S, Egecioglu E, Landgren S, et al. (2011). The role of the central Ghrelin system in reward from food and chemical drugs, Molecular and celular Endocrinology, 340(1):80-87.

46. Perello M, Zigman J. (2012). The role of Ghrelin in rewardbased eating. Biol Psychiatry. 72(5):347-353.

47. Skibicka K, Dickson S. (2013). Enteroendocrine hormonescentral effects on behavior. 13(6): 977-982.

48. Perello M, Dickson S. (2015). Ghrelin signalling on food reward:a salient link between the gut and the mesolimbic system.Journal of neuroendocrinology. 27(6): 424-434.

49. Labayen I, Ortega F, Ruiz J, et al. (2011). Role of baseline leptine and Ghrelin levels on body weight and fat mass changes after an energy- restricted diet intervention in obese women: effects on energy metabolism. 96(6): 996-1000.

50. DelParigi A, Tschöp M, Heiman M, et al. (2002). High circulating Ghrelin: a potential cause for hyperphagia and obesity in Prader-Willi Syndrome. Jclin Endocrinol Metab. 87(12): 5461-5464.

51. Kweh A, Miller J, Sulsona C, et.al. (2015). Hyperghrelinemia in Prader- Willi Syndrome begins in early infancy long before the onset of hyperphagia.Am J Med genet A. 167 A (1): 69-79.

52. Bogdanov V, Bogdanova O, Dexpert S, et al. (2020). Rewardrelated brain activity and behavior are associated with peripheral Ghrelin levels in obesity. Psychoneuroendocrinology.112.

53. Suarez A, Liu C, Cortella A, et al. (2019). Ghrelin and orexin interact to increase meal size through a descending hippocampus to hindbrain signaling pathway.Biological Psychiatry.

54. Quian J, Morris C, Caputo R, et al. (2019). Ghrelin is impacted by the endogenous circadian misalignment in humans. International Journal of Obesity. 43; 1644-1649.

55. Aly G, Hassan N, Anwar G, et al. (2020). Ghrelin, obestatin and the Ghrelin/obestatin ratio as potential mediators for food intake among obese children: a case control study. J Pediatric Endocrinol Metab.

56. Briggs D, Enriori P, Lemus M, et al. (2010). Diet induced obesity causes Ghrelin resistance in arcuate NPY/AgRP neurons. Endocrinology. 151(10):4745-4755. 
This work is licensed under Creative Commons Attribution 4.0 License

To Submit Your Article Click Here: Submit Manuscript

DOI: $10.31579 / 2640-1045 / 079$
Ready to submit your research? Choose Auctores and benefit from:

* fast, convenient online submission

* rigorous peer review by experienced research in your field

* rapid publication on acceptance

* authors retain copyrights

* unique DOI for all articles

* immediate, unrestricted online access

At Auctores, research is always in progress.

Learn more https://www.auctoresonline.org/journals/endocrinologyand-disorders 